\title{
Características sensoriais, físicas e químicas e aceitação de arroz irrigado ou de terras altas
}

\author{
Melissa Ferrari Pagnan(1), Priscila Zaczuk Bassinello(2) e Sandra Helena Prudencio(1)
}

\begin{abstract}
(1)Universidade Estadual de Londrina, Departamento de Ciência e Tecnologia de Alimentos, Caixa Postal 10.011, CEP 86051-970 Londrina, PR, Brasil. E-mail: melissa_pagnan@yahoo.com.br, sandrah@uel.br (2)Embrapa Arroz e Feijão, Rodovia GO-462, Km 12, Zona Rural, Caixa Postal 179, CEP 75375-000 Santo Antônio de Goiás, GO, Brasil. E-mail: priscila.bassinello@embrapa.br
\end{abstract}

Resumo - O objetivo deste trabalho foi caracterizar química, física e sensorialmente três genótipos de arroz polido de cultivo irrigado e cinco de terras altas. Determinaram-se: a composição centesimal, o amido, a amilose, a temperatura de gelatinização ( $\mathrm{Tg}$ ), a absorção de água ao cozimento, a cor, a textura instrumental, o perfil sensorial e a aceitação de atributos. A composição centesimal e o teor de amido variaram entre os genótipos. O 'Moti' e a linhagem N2583 foram classificados como cerosos, 'Douradão' apresentou amilose muito baixa, e os demais genótipos, amilose baixa. 'Irga 417', 'Moti' e AB101002 apresentaram Tg baixa; 'Douradão', alta; e os demais, intermediária. O 'Moti' e a linhagem N2583 crus apresentaram os maiores valores de $\mathrm{L}^{*}$; no entanto, após o cozimento, esses valores diminuíram e foram idênticos em todos os genótipos. 'Arroz-da-terra' apresentou maior a*, 'BRS Primavera' e N2583 apresentaram maior b*; e após o cozimento, houve redução desses valores. $\mathrm{Na}$ análise sensorial, destacaram-se 'AN Cambará', por pontos escuros e formato alongado; AB101002, 'Irga 417' e 'BRS Primavera', pela firmeza, cor branca e grãos soltos, que foram bem aceitos; e o 'Moti', por ser pegajoso, macio e com brilho, foi o menos aceito. Os atributos sensoriais do arroz são mais associados a características químicas, intrínsecas ao genótipo, do que à atribuição de plantio a terras altas ou irrigadas.

Termos para indexação: Oryza sativa, amilose, análise descritiva quantitativa, temperatura de gelatinização, textura.

\section{Sensory, physical and chemical characteristics, and acceptance of lowland or upland rice}

\begin{abstract}
The objective of this work was to evaluate the chemical, physical, and sensory properties of three polished rice genotypes of irrigated and five of upland cropping systems. The proximate composition, starch, amylose, gelatinization temperature (GT), water absorption during cooking, color, instrumental texture, sensory profile, and acceptance of attributes were determined. The proximate composition and starch content varied among genotypes. 'Mochi' rice and the lineage N2583 were classified as waxy; 'Douradão' showed very low amylose, and the other genotypes showed intermediate amylose. 'Irga 417', 'Mochi' rice, and AB101002 showed a low GT; 'Douradão', a high GT; and the others, an intermediate GT. Raw 'Mochi' rice and the lineage N2583 showed the highest $\mathrm{L}^{*}$ values; however, after cooking, these values reduced and were identical for all genotypes. 'Arroz-da-terra' had the highest a* value, and 'BRS Primavera' and N2583, the highest $\mathrm{b}^{*}$; after cooking, there was a reduction of these values. In sensory analysis, 'AN Cambará' stood out by dark spots and long format; AB101002, 'Irga 417' and 'BRS Primavera', by firmness, white color, and loose grains, which had good acceptance; and 'Mochi' rice, by its stickness, softness and brightness, was the less appreciated. The rice sensory attributes are most associated with chemical characteristics, intrinsic to the genotype, than with the grain attribution to upland or irrigated cropping system.
\end{abstract}

Index terms: Oryza sativa, amylose, quantitative and descriptive analysis, gelatinization temperature, texture.

\section{Introdução}

O arroz (Oryza sativa L.) é pouco utilizado como ingrediente em produtos processados e é consumido principalmente na forma de grãos inteiros, descascados, polidos e cozidos (Walter et al., 2008). A textura do arroz cozido é uma das principais características de qualidade que influencia seu consumo (Martin \& Fitzgerald, 2002; Mestres et al., 2011). Tais características estão relacionadas à composição química dos grãos 
crus (Martin \& Fitzgerald, 2002; Mestres et al., 2011), que, por sua vez, é influenciada pelo genótipo, condições e formas de cultivo, processos pós-colheita (armazenamento e beneficiamento) e forma de preparo dos grãos (Bassinello \& Naves, 2006).

$\mathrm{O}$ consumidor é atento e exigente em relação às características sensoriais específicas de textura, aparência, aroma e sabor do arroz cozido (Vieira \& Rabelo, 2006; Yang et al., 2013). Para conhecer e atender os desejos dos consumidores, é necessário avaliar o produto por meio de testes sensoriais afetivos e descritivos quantitativos (Stone \& Sidel, 2004).

No Brasil, há diferença de qualidade entre o arroz cultivado em terras altas e o irrigado, que era considerado melhor, conforme Soares et al. (2004). A fim de atender as exigências dos consumidores, novos genótipos, específicos para os dois sistemas de cultivo e com alta qualidade agronômica, culinária e sensorial estão em constante desenvolvimento (Brasil, 2015). Exemplos são 'Irga 417' e 'BRS Primavera', com padrões de qualidade "premium" e "superior", respectivamente (Champagne et al., 2010). O estudo, por meio de várias metodologias, de diferentes genótipos oriundos dos dois sistemas de cultivos, permite compreender o efeito das características intrínsecas dos genótipos e do sistema de cultivo sobre a qualidade dos grãos cozidos.

O objetivo deste trabalho foi caracterizar química, física e sensorialmente três genótipos de arroz polido de cultivo irrigado e cinco de terras altas.

\section{Material e Métodos}

Vários genótipos de arroz (Oryza sativa L.), da safra 2012/2013, foram avaliados quanto ao sistema de plantio, dos quais três de cultivo irrigado ('Irga 417', o 'Moti' e AB101002) e cinco de terras altas (N2583, 'Arroz-da-terra', 'BRS Primavera', 'Douradão' e 'AN Cambará').

As amostras do sistema irrigado, com lâmina de água controlada, foram cultivadas na fazenda Palmital, Brazabrantes, GO, a $16^{\circ} 25^{\prime} 47^{\prime \prime} \mathrm{S}$, 49 $23^{\prime} 13^{\prime \prime} \mathrm{W}$, à altitude de $762 \mathrm{~m}$. As amostras de terras altas, com irrigação em pivô central, foram cultivadas na fazenda Capivara, em Santo Antônio de Goiás, GO, a $16^{\circ} 29^{\prime} 01$ "S, $49^{\circ} 18^{\prime} 40^{\prime \prime} \mathrm{W}$, à altitude de $0 \mathrm{~m}$. Os cultivos receberam tratos culturais recomendados para o controle de pragas e doenças, adubação de NPK ao plantio e de N em cobertura, idênticas nos dois sistemas. As panículas foram secas em condições ambientais por aproximadamente uma semana, e os grãos foram beneficiados em moinho de provas Suzuki MT 10 (Máquinas Suzuki, Santa Cruz do Rio Pardo, SP, Brasil), tendo-se obtido arroz descascado e com o mesmo grau de polimento. As análises dos grãos foram conduzidas nos laboratórios do Departamento de Ciência e Tecnologia de Alimentos, da Universidade Estadual de Londrina, Londrina, PR, e no Laboratório de Pesquisa da Embrapa Arroz e Feijão, em Santo Antônio de Goiás, GO. Para as análises químicas, as amostras foram moídas em moinho modelo 33, IKA (IKA Werke GmbH \& Co. kg, Staufen, Alemanha).

Os experimentos químicos e físicos foram realizados em delineamento inteiramente casualizado, com três repetições e oito tratamentos (genótipos). As análises em cada repetição foram feitas em duplicata. Os experimentos sensoriais foram conduzidos em delineamento de blocos completos ao acaso, em que os tratamentos foram os genótipos e os blocos foram os julgadores; a análise descritiva quantitativa (ADQ) foi repetida três vezes, conforme Stone \& Sidel (2004). Os dados foram submetidos à análise de variância, e as médias sujeitas ao teste de Tukey, a 5\% de probabilidade. Os dados da ADQ também foram submetidos à análise de componentes principais, com uso do programa Statistica 7 (StatSoft Inc., Tulsa, OK, EUA).

Os teores de umidade, proteínas, lipídeos e cinzas no arroz cru foram determinados segundo os métodos da AOAC International (2006). Os teores de carboidratos totais foram determinados por diferença. Os resultados ( $\mathrm{g} 100 \mathrm{~g}^{-1}$ de amostra) foram expressos em base seca (b.s.), exceto a umidade.

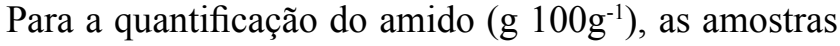
foram tratadas com $\mathrm{HCl} 0,7 \mathrm{~mol} \mathrm{~L}^{-1}$, com aquecimento em banho-maria em ebulição por $150 \mathrm{~min}$. Após resfriamento e centrifugação a $25^{\circ} \mathrm{C}, 4.500 \mathrm{~g}$, por $10 \mathrm{~min}$, em centrifuga modelo Centrifuge 5804R, (Eppendorf, Hamburg, Alemanha), o teor de açúcares redutores foi determinado nos sobrenadantes pelo método colorimétrico de Somoggyi-Nelson (Nelson, 1944). O teor de amido foi calculado multiplicandose o teor de açúcares redutores pelo fator 0,9 (AOAC International, 2006). A amilose aparente (\%) foi determinada por método colorimétrico (Martinez 
\& Cuevas, 1989), e a curva-padrão foi construída a partir de genótipos de arroz com teores crescentes de amilose $(0 ; 4,24 ; 11,35 ; 17,02$ e $23,45 \%)$, previamente determinados em cromatografia de exclusão molecular e definidos pela Rede Internacional de Qualidade de Arroz (INQR) coordenada pelo IRRI (International Rice Reaserch Institute) (Fitzgerald et al., 2009). A partir da percentagem de amilose, os grãos foram classificados como de teor: ceroso, $0-2 \%$; muito baixo, 2-9\%; baixo, 10-20\%; intermediário, 20-25\%; e alto, acima de $25 \%$.

A temperatura de gelatinização ( $\mathrm{Tg}$ ) foi estimada pelo grau de dispersão alcalina, após o tratamento das amostras com $\mathrm{KOH} 1,7 \%$ por 23 horas, a $30^{\circ} \mathrm{C}$, e leitura em escala de sete graus (Martinez \& Cuevas, 1989). A classificação seguiu os seguintes critérios: $\mathrm{Tg}$ alta, 74 a $80^{\circ} \mathrm{C}$, grau 1 a 3; Tg intermediária, 69 a $73^{\circ} \mathrm{C}$, graus 4 e 5 ; $\mathrm{Tg}$ baixa, 63 a $68^{\circ} \mathrm{C}$, graus 6 e 7. Para a medida de absorção de água $\left(\mathrm{g} 100 \mathrm{~g}^{-1}\right)$, o arroz foi cozido em água destilada $(1: 10, \mathrm{~m} / \mathrm{v})$, em banho-maria em ebulição por $10 \mathrm{~min}$, resfriado e drenado, e a diferença entre as massas do arroz cozido e cru representou a água absorvida (Singh et al., 2005). Os parâmetros de cor L* (luminosidade), a* (vermelho-verde) e b* (amarelo-azul), dos grãos crus e cozidos, foram determinados em colorímetro Color Guide 45/0 (BYK Gardner, Geretsried, Alemanha), calibrado com padrão branco $\left(\mathrm{L}^{*}=97,59, \mathrm{a}^{*}=0,39\right.$, $\left.\mathrm{b}^{*}=1,75\right)$, iluminante $\mathrm{CIE} \mathrm{D}_{65}$, iluminação em ângulo de $45^{\circ}$, ângulo de observação de $0^{\circ}$ e observação padrão CIE $10^{\circ}$. Para a medida instrumental da textura, o cozimento das amostras ( $10 \mathrm{~g}$ de arroz e $17 \mathrm{~g}$ de água, em placa de Petri) foi realizado em panela elétrica automática (PA 5 Prime Britânia), com $350 \mathrm{~mL}$ de água. A firmeza e a adesividade foram determinadas nos grãos à temperatura aproximada de $60^{\circ} \mathrm{C}$, em texturômetro TA-XT plus (Stable Micro Systems, Godalming, Inglaterra), por compressão uniaxial (Lu et al., 2013) de 10 grãos inteiros, a $95 \%$ da altura inicial, com sensor cilíndrico de $40 \mathrm{~mm}$ de diâmetro, velocidade pré-teste de $2 \mathrm{~mm} \mathrm{~s}^{-1}$, velocidade do teste de $0,5 \mathrm{~mm} \mathrm{~s}^{-1}$, velocidade pós-teste de $0,5 \mathrm{~mm} \mathrm{~s}^{-1}$, força de gatilho de $3 \mathrm{~g}$, e distância entre o sensor e a plataforma de análise de $5 \mathrm{~mm}$. A máxima força de compressão $(\mathrm{N})$ indicou a firmeza, e a energia de adesão do retorno do sensor indicou a adesividade $(\mathrm{N} \mathrm{s})$.
Os genótipos AB101002, 'AN Cambará', 'Douradão', 'Irga 417', 'Moti' e 'BRS Primavera' foram submetidos aos testes sensoriais de análise descritiva quantitativa (ADQ) e de aceitação de atributos (Stone \& Sidel, 2004), após aprovação pelo Comitê de Ética em Pesquisa envolvendo Seres Humanos (UEL, parecer 195/2012, CAAE 08873812.2.0000.5231). Os genótipos N2583 e 'Arroz-da-terra' contribuíram como amostras de referência para a definição e quantificação de atributos na $\mathrm{ADQ}$, conforme indicação da equipe de avaliação sensorial. As amostras foram cozidas em água (1:2, $\mathrm{m} / \mathrm{v}$ ), em panela elétrica automática PA 5 Prime Britânia, conforme as instruções do fabricante, por 33 ('Douradão'), 29 ('BRS Primavera'), 28 ('NA Cambará' e 'Irga 417'), 27 (AB101002), e 23 minutos ('Moti'). $\mathrm{Na}$ análise sensorial, o cozimento seguiu a recomendação do fabricante da panela, que é a forma mais usual utilizada pelo consumidor. Os testes foram realizados em cabines individuais, sob luz do dia $\mathrm{D}_{65}$. Em cada teste, $30 \mathrm{~g}$ de cada amostra, à temperatura aproximada de $60^{\circ} \mathrm{C}$, foram servidos monadicamente, em ordem aleatória, em copo descartável de isopor codificado com números aleatórios de três dígitos. Utilizou-se água potável à temperatura ambiente, para limpar a boca antes e entre as provas.

A partir de 25 voluntários, 12 julgadores foram selecionados para participar da ADQ, com base no desempenho em testes de reconhecimento de gostos e odores básicos e de ordenação de intensidade de dureza. A terminologia descritiva dos atributos foi desenvolvida pelos julgadores selecionados, com uso do método de rede (Tabela 1). Os julgadores, em consenso, definiram os atributos, sugeriram as amostras de referência e elaboraram a ficha de avaliação. A escala de medida foi a não estruturada de $15 \mathrm{~cm}$, ancorada a $1,5 \mathrm{~cm}$ em cada extremidade, com palavras que indicam o aumento da intensidade de cada atributo da esquerda para a direita (Stone \& Sidel, 2004). Os julgadores foram treinados para identificar e quantificar os atributos com uso das amostras de referência (Tabela 1). Após 8 sessões de treinamento, de aproximadamente uma hora cada, procedeu-se à nova seleção de julgadores, em que três genótipos ('Irga 417', 'Douradão' e 'AN Cambará') foram avaliados, em delineamento de blocos completos ao acaso repetido três vezes. Os dados de cada julgador para cada atributo foram submetidos 
à análise de variância, com duas fontes de variação - genótipos e repetições - e teste F. Os critérios de seleção foram: o poder de discriminação ( $p$ de $\mathrm{F}_{\text {amostra }} \leq 0,5$ ); repetibilidade ( $\mathrm{p}$ de $\mathrm{F}_{\text {repetição }} \geq 0,05$ ); e a concordância de cada julgador com a equipe em cada atributo, avaliada por meio de comparação das médias das amostras de cada julgador com as médias da equipe (Stone \& Sidel, 2004). Consideraram-se treinados 10 julgadores (equipe final), que avaliaram os seis genótipos de arroz.

No teste de laboratório de aceitação de atributos (aparência, aroma, sabor, textura e global), empregaram-se 54 consumidores de arroz e uma escala hedônica (Stone \& Sidel, 2004), estruturada de 9 pontos: 1, desgostei muito; 5, nem gostei/nem desgostei; 9, gostei muito.

\section{Resultados e Discussão}

A composição química variou entre os oito genótipos de arroz (Tabela 2). A umidade situou-se em valor próximo ao permitido pela legislação brasileira para a comercialização de arroz beneficiado $\left(14{\left.\mathrm{~g} 100 \mathrm{~g}^{-1}\right)}^{-1}\right.$ (Brasil, 2009), percentual que auxilia a conservação do grão. O teor proteico dos genótipos encontrou-se dentro do intervalo de valores para arroz polido -5 a $13 \%$, base úmida de $12 \%$ - (Kennedy \& Burlingame, 2003). Os genótipos 'Moti' e AB101002, do cultivo irrigado, apresentaram menor teor proteico do que os genótipos de terras altas. Os genótipos estão de acordo quanto ao conteúdo de lipídeos de menos de $1 \%$, normalmente encontrado em arroz polido (Naves, 2007), exceto a linhagem N2583, que se destacou pelo

Tabela 1. Atributos, definições e referências utilizados na análise descritiva quantitativa de diferentes genótipos de arroz.

\begin{tabular}{|c|c|c|}
\hline Atributo & Definição & Amostra de referência \\
\hline \multicolumn{3}{|l|}{ Aparência } \\
\hline Solto & $\begin{array}{l}\text { Grãos separados uns dos } \\
\text { outros e que não apresentam } \\
\text { aderência entre eles }\end{array}$ & $\begin{array}{l}\text { Pouco: } 100 \mathrm{~g} \text { de arroz branco polido, cozido }{ }^{(1)} \mathrm{em} 200 \mathrm{~mL} \text { de água, do 'Moti' - Embrapa } \\
\text { Muito: } 100 \mathrm{~g} \text { de arroz parboilizado polido, cozido em } 150 \mathrm{~mL} \text { de água, marca Tio João }\end{array}$ \\
\hline $\begin{array}{l}\text { Formato } \\
\text { alongado }\end{array}$ & $\begin{array}{l}\text { Refere-se ao comprimento } \\
\text { dos grãos }\end{array}$ & $\begin{array}{l}\text { Pouco: } 100 \mathrm{~g} \text { de arroz branco polido, classe curto, cozido em } 200 \mathrm{~mL} \text { de água, marca Caldo Bom } \\
\text { Muito: } 100 \mathrm{~g} \text { de arroz branco polido, classe longo fino, cozido em } 200 \mathrm{~mL} \text { de água, marca Prato Fino }\end{array}$ \\
\hline Brilho & $\begin{array}{l}\text { Refere-se à intensidade de } \\
\text { reflexão da luz pelas amostras }\end{array}$ & $\begin{array}{l}\text { Pouco: } 100 \mathrm{~g} \text { de arroz branco polido, cozido em } 200 \mathrm{~mL} \text { de água, da cultivar 'Irga 417' - Embrapa } \\
\text { Muito: } 100 \mathrm{~g} \text { de arroz branco polido, cozido em } 200 \mathrm{~mL} \text { de água, Moti - Embrapa }\end{array}$ \\
\hline Cor & $\begin{array}{l}\text { Refere-se à brancura } \\
\text { dos grãos }\end{array}$ & $\begin{array}{l}\text { Pouco: } 100 \mathrm{~g} \text { de arroz parboilizado polido, cozido em } 150 \mathrm{~mL} \text { de água, marca Tio João } \\
\text { Muito: } 100 \mathrm{~g} \text { de arroz branco polido, classe longo fino, cozido em } 200 \mathrm{~mL} \text { de água, marca Prato Fino }\end{array}$ \\
\hline $\begin{array}{l}\text { Pontos } \\
\text { escuros }\end{array}$ & $\begin{array}{l}\text { Presença de pontos marrons } \\
\text { na superfície dos grãos }\end{array}$ & $\begin{array}{l}\text { Pouco: } 100 \mathrm{~g} \text { de arroz branco polido, classe longo fino, cozido em } 200 \mathrm{~mL} \text { de água, marca Prato Fino } \\
\text { Muito: } 100 \mathrm{~g} \text { de arroz branco polido, cozido em } 200 \mathrm{~mL} \text { de água, de arroz-da-terra - Embrapa }\end{array}$ \\
\hline Quebrado & $\begin{array}{l}\text { Falta de integridade } \\
\text { dos grãos }\end{array}$ & $\begin{array}{l}\text { Pouco: } 100 \mathrm{~g} \text { de arroz branco polido, classe longo fino, cozido em } 200 \mathrm{~mL} \text { de água, marca Prato Fino } \\
\text { Muito: } 100 \mathrm{~g} \text { de quirera de arroz polido, obtido de beneficiadora de arroz, cozido em } 200 \mathrm{~mL} \text { de água }\end{array}$ \\
\hline \multicolumn{3}{|l|}{ Aroma } \\
\hline Arroz cozido & $\begin{array}{l}\text { Aroma característico } \\
\text { de arroz cozido }\end{array}$ & $\begin{array}{l}\text { Pouco: } 100 \mathrm{~g} \text { de arroz branco polido, classe longo fino, cozido em } 200 \mathrm{~mL} \text { de água, marca Prato Fino } \\
\text { resfriado em geladeira por } 10 \mathrm{~min}\end{array}$ \\
\hline Arroz integral & $\begin{array}{l}\text { Aroma característico } \\
\text { de arroz integral }\end{array}$ & $\begin{array}{l}\text { Pouco: } 100 \text { g de arroz branco polido, classe longo fino, cozido em } 200 \mathrm{~mL} \text { de água, marca Prato Fino } \\
\text { Muito: } 100 \mathrm{~g} \text { de arroz integral, cozido em } 300 \mathrm{~mL} \text { de água, da marca Tio João }\end{array}$ \\
\hline \multicolumn{3}{|l|}{ Sabor } \\
\hline $\begin{array}{l}\text { Típico de } \\
\text { arroz }\end{array}$ & $\begin{array}{l}\text { Sabor típico } \\
\text { de arroz cozido }\end{array}$ & $\begin{array}{l}\text { Pouco: } 100 \mathrm{~g} \text { de arroz branco polido, classe longo fino, cozido em } 200 \mathrm{~mL} \text { de água, marca Prato Fino, por } \\
\text { aproximadamente } 10 \mathrm{~min} \text { e resfriado em geladeira } \\
\text { Muito: } 100 \mathrm{~g} \text { de arroz branco polido, classe longo fino, cozido em } 200 \mathrm{~mL} \text { de água, marca Prato Fino }\end{array}$ \\
\hline Arroz integral & $\begin{array}{c}\text { Sabor típico } \\
\text { de arroz integral }\end{array}$ & $\begin{array}{l}\text { Pouco: } 100 \mathrm{~g} \text { de arroz branco polido, classe longo fino, cozido em } 200 \mathrm{~mL} \text { de água, marca Prato Fino } \\
\text { Muito: } 100 \mathrm{~g} \text { de arroz integral cozido em } 300 \mathrm{~mL} \text { de água, da marca Tio João }\end{array}$ \\
\hline \multicolumn{3}{|l|}{ Textura } \\
\hline Maciez & $\begin{array}{l}\text { Facilidade de rompimento dos } \\
\text { grãos durante a mastigação }\end{array}$ & $\begin{array}{l}\text { Pouco: } 100 \mathrm{~g} \text { de arroz branco polido, classe longo fino, cozido em } 200 \mathrm{~mL} \text { de água, marca Prato Fino por } \\
\text { aproximadamente } 10 \mathrm{~min} \\
\text { Muito: } 100 \mathrm{~g} \text { de arroz branco polido, classe longo fino, cozido em } 200 \mathrm{~mL} \text { de água, marca Prato Fino }\end{array}$ \\
\hline Pegajoso & $\begin{array}{l}\text { Aderência do arroz à boca } \\
\text { e aos dentes durante a } \\
\text { mastigação }\end{array}$ & $\begin{array}{l}\text { Pouco: } 100 \mathrm{~g} \text { de arroz parboilizado polido cozido em } 200 \mathrm{~mL} \text { de água, marca Tio João } \\
\text { Muito: } 100 \mathrm{~g} \text { de arroz branco polido cozido em } 200 \mathrm{~mL} \text { de água, Moti - Embrapa }\end{array}$ \\
\hline
\end{tabular}

${ }^{(1)}$ Cozimento automático em panela elétrica PA 5 Prime Britânia. 
conteúdo superior. $\mathrm{O}$ maior teor de cinzas (AB101002) foi o dobro do menor ('Douradão') e está próximo ao conteúdo médio (0,3\%) em arroz polido (Naves, 2007). Os genótipos de cultivo irrigado 'Moti' e AB101002 apresentaram o maior teor de carboidratos totais, e o genótipo N2583 (de terras altas), o menor. Resultados próximos (83 a 89\%) foram observados em diferentes genótipos por Kaminski et al. (2013) e Polesi (2014). O conteúdo de amido variou entre os genótipos, cujos resultados foram coerentes $(88 \%)$ em arroz polido (Naves, 2007), e não se observou distinção quanto ao sistema de cultivo. Considerando-se o teor de amilose, os genótipos classificaram-se como: cerosos, 'Moti' (irrigado) e N2583 (terras altas); de amilose muito baixa, 'Douradão'; e, de amilose baixa, os outros genótipos. Garcia et al. (2011), em estudo de diferentes genótipos de terras altas e irrigado, classificaram 'BRS Primavera' e 'Irga 417' como de teor amilose intermediária. A diferença pode estar vinculada ao uso de diferentes valores de referência, além da época de cultivo (Bassinello \& Naves, 2006) dos genótipos; o local do experimento foi o mesmo do presente estudo. As diferenças quantitativas na composição química dos grãos dos genótipos estudados estão, provavelmente, mais associadas às caracteristicas intrínsecas genotípicas dos grãos do que ao sistema de cultivo irrigado ou de terras altas.

Os genótipos de cultivo irrigado 'Irga 417', 'Moti' e AB101002 apresentaram Tg baixa. Os genótipos de terras altas N2583, 'Arroz-da-terra', 'BRS Primavera' e 'AN Cambará' apresentaram Tg intermediária, e o 'Douradão', Tg alta (Tabela 3). Garcia et al. (2011)

Tabela 2. Composição química dos grãos de diferentes genótipos de arroz cru ${ }^{(1)}$.

\begin{tabular}{|c|c|c|c|c|c|c|c|}
\hline Genótipo & Umidade & Proteínas & Lipídeos & $\left.\mathrm{g}^{-1}\right)$ Cinzas & Carboidratos totais $^{(2)}$ & Amido & $\begin{array}{c}\text { Amilose } \\
(\%)\end{array}$ \\
\hline & \multicolumn{7}{|c|}{ Cultivo irrigado } \\
\hline 'Irga 417' & $13,60 \pm 0,09 \mathrm{~d}$ & $9,89 \pm 0,07 \mathrm{~d}$ & $0,22 \pm 0,02 \mathrm{f}$ & $0,48 \pm 0,03 \mathrm{~cd}$ & $89,41 \pm 0,09 \mathrm{~b}$ & $89,28 \pm 0,96 a$ & $19,44 \pm 0,47 \mathrm{a}$ \\
\hline 'Moti' & $14,37 \pm 0,06 \mathrm{a}$ & $9,05 \pm 0,13 \mathrm{e}$ & $0,67 \pm 0,03 b$ & $0,40 \pm 0,02 \mathrm{e}$ & $89,87 \pm 0,11 \mathrm{a}$ & $87,71 \pm 1,38 \mathrm{abc}$ & $-0,18 \pm 0,17 \mathrm{e}$ \\
\hline \multirow[t]{2}{*}{$\mathrm{AB} 101002$} & $13,79 \pm 0,10 \mathrm{c}$ & $9,04 \pm 0,12 \mathrm{e}$ & $0,64 \pm 0,04 \mathrm{~b}$ & $0,57 \pm 0,05 \mathrm{a}$ & $89,75 \pm 0,13 \mathrm{a}$ & $86,05 \pm 1,29 \mathrm{cde}$ & $19,43 \pm 0,97 \mathrm{a}$ \\
\hline & \multicolumn{7}{|c|}{ Cultivo de terras altas } \\
\hline N2583 & $14,43 \pm 0,12 \mathrm{a}$ & $12,90 \pm 0,20 \mathrm{a}$ & $1,35 \pm 0,06 \mathrm{a}$ & $0,55 \pm 0,04 \mathrm{ab}$ & $85,20 \pm 0,19 \mathrm{f}$ & $83,92 \pm 0,60 \mathrm{f}$ & $-0,69 \pm 0,17 \mathrm{e}$ \\
\hline 'Arroz-da-terra' & $13,26 \pm 0,04 \mathrm{e}$ & $13,12 \pm 0,15 \mathrm{a}$ & $0,50 \pm 0,02 \mathrm{c}$ & $0,49 \pm 0,02 \mathrm{c}$ & $85,89 \pm 0,14 \mathrm{e}$ & $84,34 \pm 0,97 \mathrm{ef}$ & $18,93 \pm 0,39 \mathrm{a}$ \\
\hline 'BRS Primavera' & $13,04 \pm 0,03 \mathrm{f}$ & $12,00 \pm 0,14 \mathrm{~b}$ & $0,60 \pm 0,03 \mathrm{~b}$ & $0,43 \pm 0,02 \mathrm{de}$ & $86,96 \pm 0,15 \mathrm{~d}$ & $86,59 \pm 0,84 \mathrm{bcd}$ & $15,68 \pm 0,68 \mathrm{c}$ \\
\hline 'Douradão' & $14,14 \pm 0,20 \mathrm{~b}$ & $10,18 \pm 0,27 \mathrm{~d}$ & $0,37 \pm 0,03 \mathrm{e}$ & $0,29 \pm 0,02 \mathrm{f}$ & $89,15 \pm 0,27 b$ & $88,40 \pm 1,36 \mathrm{ab}$ & $9,35 \pm 0,38 \mathrm{~d}$ \\
\hline 'AN Cambará' & $13,82 \pm 0,03 \mathrm{c}$ & $10,99 \pm 0,21 \mathrm{c}$ & $0,43 \pm 0,03 \mathrm{~d}$ & $0,50 \pm 0,02 \mathrm{bc}$ & $88,07 \pm 0,23 \mathrm{c}$ & $85,52 \pm 1,31 \mathrm{def}$ & $17,52 \pm 0,17 \mathrm{~b}$ \\
\hline
\end{tabular}

${ }^{(1)}$ Médias seguidas de letras iguais, nas colunas, não diferem pelo teste de Tukey, a 5\% de probabilidade. Valores médios de duas determinações em cada repetição \pm desvio-padrão. ${ }^{(2)}$ Carboidratos totais, obtidos por diferença (100 - proteínas - lipídeos - cinzas).

Tabela 3. Propriedades físicas dos grãos de diferentes genótipos de arroz ${ }^{(1)}$.

\begin{tabular}{|c|c|c|c|c|c|c|c|c|c|c|}
\hline \multirow[t]{2}{*}{ Genótipo } & \multirow[t]{2}{*}{$\mathrm{Tg}$} & \multirow{2}{*}{$\begin{array}{c}\text { Absorção de } \\
\text { água }\left(\mathrm{g} 100 \mathrm{~g}^{-1}\right)\end{array}$} & \multirow{2}{*}{$\begin{array}{l}\text { Firmeza } \\
(\mathrm{N})\end{array}$} & \multirow{2}{*}{$\begin{array}{l}\text { Adesividade } \\
\text { (N.s) }\end{array}$} & \multicolumn{3}{|c|}{ Cor-arroz cru } & \multicolumn{3}{|c|}{ Cor-arroz cozido } \\
\hline & & & & & $\mathrm{L}^{*}$ & $\mathrm{a}^{*}$ & $\mathrm{~b}^{*}$ & $\mathrm{~L}^{*}$ & $\mathrm{a}^{*}$ & $\mathrm{~b}^{*}$ \\
\hline & \multicolumn{10}{|c|}{ Cultivo irrigado } \\
\hline 'Irga 417' & Baixa & $118,58 \pm 1,27 d$ & $159,4 \pm$ & $-3,9 \pm 0,5 \mathrm{~d}$ & $65,9 \pm 2,5 b$ & $3,9 \pm 0,2 \mathrm{~cd}$ & $5,4 \pm 0,4 \mathrm{bc}$ & $66,8 \pm 5,2 \mathrm{a}$ & $2,9 \pm 0,3 b$ & $-1,3 \pm 0,3 \mathrm{de}$ \\
\hline 'Moti' & Baixa & $112,62 \pm 0,88 \mathrm{e}$ & 134,6 & $-20,9 \pm 2,6 \mathrm{a}$ & $80,4 \pm 2,9 \mathrm{a}$ & $3,8 \pm 0,2 \mathrm{~cd}$ & $6,1 \pm 0,7 \mathrm{~b}$ & $66,6 \pm 4,6 \mathrm{a}$ & $2,4 \pm 0,3 b$ & $0,3 \pm 0,2 \mathrm{c}$ \\
\hline \multirow[t]{2}{*}{$\mathrm{AB} 101002$} & aixa & $136,69 \pm 1$ & $157,8 \pm 5,3 \mathrm{abc}$ & $-4,9 \pm 0,9 \mathrm{~cd}$ & $65,2 \pm 2,9 \mathrm{~b}$ & $3,7 \pm 0,2 \mathrm{~cd}$ & $5,9 \pm 0,9 \mathrm{bc}$ & $64,8 \pm 2,9 \mathrm{a}$ & $2,9 \pm 0,2 \mathrm{~b}$ & $-1,5 \pm 0,3 \mathrm{de}$ \\
\hline & \multicolumn{10}{|c|}{ Cultivo de terras altas } \\
\hline N2583 & Intermediária & $101,44 \pm 0,85 \mathrm{f}$ & 139,5 & $-23,2 \pm 1,2 \mathrm{a}$ & $79,5 \pm 2,2 \mathrm{a}$ & $4,8 \pm 0,7 \mathrm{~b}$ & & $66,6 \pm 3,3 \mathrm{a}$ & $2,6 \pm 0,5 \mathrm{~b}$ & $5,2 \pm 1,6 \mathrm{a}$ \\
\hline 'Arroz-da-terra' & Intermediária & $104,02 \pm 2,82 \mathrm{f}$ & $174,1 \pm 7,5 \mathrm{a}$ & $-7,0 \pm 1,4 \mathrm{c}$ & $67,6 \pm 4,7 \mathrm{~b}$ & $5,8 \pm 0,3 \mathrm{a}$ & $5,9 \pm 0,7 \mathrm{bc}$ & $66,2 \pm 2,1 \mathrm{a}$ & $5,9 \pm 0,4 \mathrm{a}$ & $1,8 \pm 0,6 b$ \\
\hline 'BRS Primavera' & Intermediária & $126,62 \pm 2,80 \mathrm{c}$ & $147,7 \pm 4,5 \mathrm{bcd}$ & $-5,5 \pm 1,1 \mathrm{~cd}$ & $69,3 \pm 2,3 b$ & $3,7 \pm 0,1 \mathrm{~cd}$ & $7,7 \pm 0,6 \mathrm{a}$ & $66,1 \pm 3,0 \mathrm{a}$ & $2,6 \pm 0,2 b$ & $-0,6 \pm 0,2 \mathrm{~cd}$ \\
\hline 'Douradão' & Alta & $102,13 \pm 3,53 \mathrm{f}$ & $167,6 \pm 10,5 \mathrm{a}$ & $-16,5 \pm 2,0 \mathrm{~b}$ & $67,7 \pm 3,0 \mathrm{~b}$ & $3,4 \pm 0,1 \mathrm{~d}$ & $4,8 \pm 0,4 \mathrm{c}$ & $64,6 \pm 3,7 \mathrm{a}$ & $2,5 \pm 0,2 b$ & $-1,8 \pm 0,3 \mathrm{e}$ \\
\hline 'AN Cambará' & Intermediária & $219,90 \pm 3,03 a$ & $141,9 \pm 9,1 \mathrm{~cd}$ & $-6,4 \pm 0,9 \mathrm{~cd}$ & $66,2 \pm 3,4 \mathrm{~b}$ & $4,2 \pm 0,2 \mathrm{bc}$ & $6,2 \pm 0,5 \mathrm{~b}$ & $64,0 \pm 3,5 \mathrm{a}$ & $2,8 \pm 0,3 \mathrm{~b}$ & $-0,6 \pm 0,3 \mathrm{~cd}$ \\
\hline
\end{tabular}

${ }^{(1)}$ Médias seguidas de letras iguais, nas colunas, em cada propriedade, não diferem pelo teste de Tukey, a $5 \%$ de probabilidade. Valores médios de duas determinações em cada repetição \pm desvio-padrão. Tg, temperatura de gelatinização. Tg alta, 74 a $80{ }^{\circ} \mathrm{C}$; $\mathrm{Tg}$ intermediária, 69 a $73{ }^{\circ} \mathrm{C} ; \mathrm{Tg}$ baixa, 63 a $68^{\circ} \mathrm{C}$. $\mathrm{L}^{*}: 0$ (branco) a 100 (preto); a*, vermelho (+), verde (-); b*, amarelo (+), azul (-). 
também observaram classificação semelhante de arroz de cultivo irrigado e de terras altas, entre os genótipos o 'Irga 417' e 'BRS Primavera'. A baixa $\mathrm{Tg}$ observada nos genótipos irrigados indica que haverá necessidade de menos água e tempo para o cozimento do arroz, do que para arroz com Tg alta ou intermediária (Martinez \& Cuevas, 1989; Ferreira et al., 2005, Bassinello \& Naves, 2006; Cuevas et al., 2010). Além da disponibilidade de água, a Tg está relacionada à proporção e organização das moléculas de amilose e amilopectina, complexo amilose/lipídeo, grau de cristalinidade e tamanho das cadeias de amilopectina nos grânulos (Zhou et al., 2002). Dentre os genótipos, o 'AN Cambará' destacou-se pela maior absorção de água durante o cozimento e N2583, 'Arroz-da-terra' e 'Douradão' mostraram as menores absorções. A quantidade de água absorvida pelo arroz durante o cozimento é influenciada pelo conteúdo de amilose, Tg e conteúdo de proteínas (Taylor \& Duodu, 2009), assim, a maior absorção de água pelos grãos 'AN Cambará', em comparação ao 'Arroz-da-terra' e 'BRS Primavera', pode ser explicada por seu menor conteúdo de proteínas. A baixa absorção de água pelos grãos de 'Douradão' pode estar relacionada ao procedimento de medida empregado, pelo qual o tempo de cozimento foi fixo para todos os genótipos. Assim, 'Douradão', com possível taxa de absorção mais lenta, não teve tempo suficiente para a absorção de água, uma vez que grãos com alta Tg necessitam de mais tempo para cozimento (Ferreira et al., 2005, Bassinello \& Naves, 2006). Não se observaram diferenças de absorção de água quanto aos sistemas de cultivo dos genotipos, e o resultado relacionouse mais às características químicas e físico-químicas dos grãos. Quanto à textura instrumental dos grãos cozidos, os genótipos mais firmes, exceto 'Douradão', continham mais amilose. $\mathrm{O}$ efeito do conteúdo de amilose sobre a adesividade foi inverso. Tais resultados estão coerentes com a literatura (Bassinello \& Naves, 2006; Vieira \& Rabelo, 2006; Lu et al., 2013; Tian et al., 2014). 'Douradão', apesar do conteúdo de amilose muito baixo, mostrou grãos cozidos firmes e adesivos. A firmeza pode ser atribuída ao centro do grão semiduro, comportamento resultante da alta $\mathrm{Tg}$ (Ferreira et al., 2005). O menor conteúdo de proteína nem sempre resulta em grãos mais adesivos (Martin \& Fitzgerald, 2002; Mestres et al., 2011), pois o 'Moti' continha menos proteína do que N2583 (Talela 2), e ambos apresentaram comportamento semelhante de firmeza e adesividade. Os grãos crus dos genótipos N2583 e 'Moti' apresentaram os maiores valores de $L^{*}$, ou seja, eram mais brancos do que os demais, o que está de acordo com a aparência branca e opaca de arroz ceroso (Taylor \& Duodu, 2009). Porém, após o cozimento, houve redução de $\mathrm{L}^{*}$, que se tornou idêntico em todos os genótipos. Nas amostras cruas, 'Arroz-da-terra' mostrou o maior valor do parâmetro a*, e N2583 e 'BRS Primavera', os maiores valores de $b^{*}$; porém, após o cozimento, notou-se uma redução dos valores de ambos os parâmetros, exceto o valor de a* do 'Arroz-da-terra'. Os valores de a* e $b^{*}$ encontrados indicam baixa intensidade de cor nos genótipos estudados, que tendem para o branco, característica desejada pelo consumidor (Tian et al., 2014). Os valores de L*, a* e b* observados estão próximos aos relatados na literatura sobre o arroz branco (Fonseca et al., 2011; Bett-Garber et al., 2012).

Para a interpretação da análise de componentes principais, dos dados sensoriais da ADQ dos genótipos AB101002, 'AN Cambará', 'Douradão', 'Irga 417', 'Moti' e 'BRS Primavera' cozidos (Figura 1), utilizaram-se os dois primeiros componentes principais (CP) com explicação acumulada de $72,85 \%$ da variabilidade dos dados originais, o que atende o critério mínimo sugerido por Jolliffe (2002). Consideraram-se relevantes os atributos (vetores) com coeficientes de correlação superiores a 0,6 (valor absoluto) com cada CP. Para a explicação (38,76\%) do CP1, contribuíram: a aparência solta (correlação positiva), a pegajosidade, o brilho e a maciez (correlação negativa); assim, a $\mathrm{CP} 1$ representou a importância do atributo textura, na caracterização de arroz cozido, conforme outros estudos (Martin \& Fitzgerald, 2002; Mestres et al., 2011). Para o CP2 (34,09\% de explicação), contribuíram: o formato alongado, os pontos escuros, o aroma e o sabor de arroz integral (correlação positiva), a cor branca, os quebrados e o aroma de arroz cozido (correlação negativa). O sabor típico de arroz apresentou baixa contribuição discriminativa $(<0,6)$. De acordo com a localização dos genótipos no plano CP 1 x CP 2: o 'Moti' destacou-se pelos grãos pegajosos, o brilho e a maciez; 'Douradão', pelos grãos quebrados e o aroma de arroz cozido; 'AN Cambará', pelos pontos escuros e o formato alongado; AB101002, 'Irga 417' e 'BRS Primavera' formaram um grupo caracterizado 

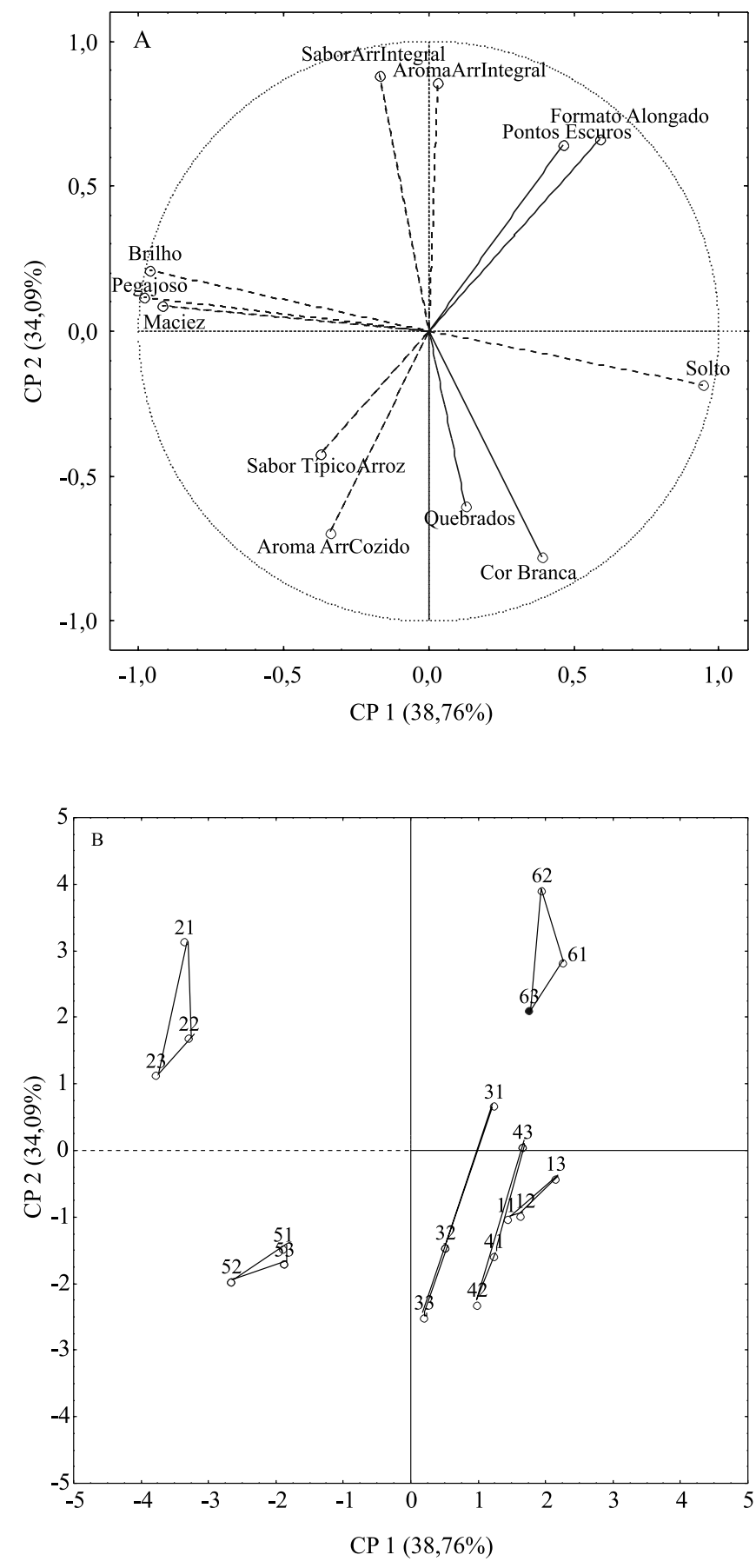

Figura 1. Projeções dos atributos sensoriais quanto a (A), atributos - aparência (solto, formato alongado, brilho, cor branca, pontos escuros e quebrados), aroma (arroz cozido e arroz integral), sabor (arroz cozido e arroz integral), textura (maciez e pegajoso) -; e projeções quanto a (B), genótipos de arroz - para genótipos e repetições: 'Irga 417', 11, 12, 13; Moti 21, 22, 23; AB101002, 31, 32, 33; 'BRS Primavera', 41, 42, 43; 'Douradão', 51, 52, 53; 'AN Cambará', 61, 62, 63; sobre plano fatorial (CP 1 x CP 2). pela cor branca e pelos grãos quebrados e soltos (Figura 1 A e B). Quanto aos atributos sensoriais dos grãos cozidos, não houve discriminação de genótipos em relação ao sistema de cultivo, diferentemente de Garcia et al. (2011) que, por meio da análise de agrupamento, observaram que genótipos de terras altas apresentavam grãos macios e soltos, enquanto os de cultivo irrigado eram macios e pegajosos.

Apesar de a análise de componentes principais indicar a importância discriminativa dos atributos de aroma e sabor, os genótipos avaliados não se diferenciaram quanto a eles (Tabela 4). Porém, as notas de intensidade do aroma e sabor típicos de arroz cozido foram mais elevadas do que as de arroz integral, resultado esperado quanto ao arroz polido. $\mathrm{O}$ fato de os genótipos AB101002, 'AN Cambará', 'Irga 417' e 'BRS Primavera' apresentarem aparência mais solta e textura menos macia e pegajosa do que o 'Douradão' e o 'Moti' (Tabela 4) está associado ao teor de amilose (Tabela 2), o que confirma que grãos crus com maior teor de amilose resultam em grãos cozidos mais firmes, soltos e menos pegajosos (Lu et al., 2013). 'Douradão', diferentemente do resultado da medida de firmeza instrumental (Tabela 3), mostrou-se macio na avaliação sensorial (Tabela 4). Este resultado, provavelmente, está relacionado ao procedimento de cozimento usado para cada análise. Nesse processo, os grãos de 'Douradão' puderam completar seu cozimento, apesar de demorar mais tempo do que os dos demais genótipos, o que está coerente com sua alta $\mathrm{Tg}$ (Ferreira et al., 2005). Entre os genótipos, o 'AN Cambará' apresentou o formato mais alongado e com mais pontos escuros, característica própria do genótipo. Os grãos de 'Moti' se destacaram, ainda, pelo maior brilho e a menor brancura, atributos relacionados ao amido ceroso, que é composto apenas por amilopectina (Ferreira et al., 2005). 'Douradão' e 'BRS Primavera' apresentaram mais grãos quebrados do que o 'Moti', provavelmente, em razão do maior tempo necessário para o cozimento dos primeiros em comparação ao 'Moti', resultado coerente com a Tg de cada genótipo (Ferreira et al., 2005). As características sensoriais de aparência e textura do arroz cozido foram mais influenciadas pelas características intrínsecas, como a composição química de cada genótipo, do que pelo sistema de plantio.

Quanto à aceitação (Tabela 4), destacaramse: 'Moti', por ser o menos aceito, e 'Irga 417', 'BRS Primavera' e AB101002, por terem recebido 
Tabela 4. Perfil sensorial da análise descritiva quantitativa e aceitação de diferentes genótipos de arroz cozido ${ }^{(1)}$.

\begin{tabular}{|c|c|c|c|c|c|c|}
\hline \multirow[t]{2}{*}{ Atributo } & \multicolumn{3}{|c|}{ Cultivo irrigado } & \multicolumn{3}{|c|}{ Cultivo de terras altas } \\
\hline & 'Irga 417' & 'Moti' & 'AB101002' & 'BRS Primavera' & 'Douradão' & 'AN Cambará \\
\hline & \multicolumn{6}{|c|}{ Perfil sensorial da análise descritiva quantitativa ${ }^{(2)}$} \\
\hline Solto & $10,08 \mathrm{a}$ & $1,44 b$ & $9,87 \mathrm{a}$ & $10,44 \mathrm{a}$ & $2,76 b$ & $9,08 \mathrm{a}$ \\
\hline Formato alongado & $9,94 \mathrm{~b}$ & $8,74 \mathrm{bc}$ & $9,40 \mathrm{bc}$ & $9,41 \mathrm{bc}$ & $7,73 \mathrm{c}$ & $12,19 \mathrm{a}$ \\
\hline Brilho & $2,06 \mathrm{c}$ & $13,25 \mathrm{a}$ & $2,65 \mathrm{c}$ & $2,80 \mathrm{c}$ & $8,00 \mathrm{~b}$ & $2,04 \mathrm{c}$ \\
\hline Cor branca & $10,82 \mathrm{a}$ & $5,23 \mathrm{c}$ & $9,76 \mathrm{ab}$ & $9,54 \mathrm{ab}$ & $10,41 \mathrm{a}$ & $7,26 \mathrm{bc}$ \\
\hline Pontos escuros & $2,38 \mathrm{~b}$ & $1,70 \mathrm{~b}$ & $2,18 \mathrm{~b}$ & $2,09 \mathrm{~b}$ & $2,32 b$ & $9,26 \mathrm{a}$ \\
\hline Quebrados & $5,26 \mathrm{ab}$ & $3,82 b$ & $5,63 \mathrm{ab}$ & $6,51 \mathrm{a}$ & $6,45 \mathrm{a}$ & $4,98 \mathrm{ab}$ \\
\hline Aroma de arroz cozido & $11,64 \mathrm{a}$ & $11,66 \mathrm{a}$ & $11,84 \mathrm{a}$ & $11,92 \mathrm{a}$ & $11,81 \mathrm{a}$ & $10,63 a$ \\
\hline Aroma de arroz integral & $2,19 \mathrm{a}$ & $3,13 \mathrm{a}$ & $2,47 \mathrm{a}$ & $2,29 \mathrm{a}$ & $1,85 \mathrm{a}$ & $3,33 \mathrm{a}$ \\
\hline Sabor típico de arroz & $10,69 \mathrm{a}$ & $11,20 \mathrm{a}$ & $11,73 a$ & $11,39 \mathrm{a}$ & $11,97 \mathrm{a}$ & $11,05 \mathrm{a}$ \\
\hline Sabor de arroz integral & $1,61 \mathrm{a}$ & $2,69 \mathrm{a}$ & $1,58 \mathrm{a}$ & $1,64 \mathrm{a}$ & $1,48 \mathrm{a}$ & $2,61 \mathrm{a}$ \\
\hline Maciez & $9,87 \mathrm{~b}$ & $13,11 \mathrm{a}$ & $10,98 \mathrm{~b}$ & $9,73 b$ & $12,74 \mathrm{a}$ & $10,60 \mathrm{~b}$ \\
\hline \multirow[t]{2}{*}{$\underline{\text { Pegajoso }}$} & $2,51 \mathrm{c}$ & $13,07 \mathrm{a}$ & $3,78 \mathrm{c}$ & $2,91 \mathrm{c}$ & $10,44 \mathrm{~b}$ & $2,74 \mathrm{c}$ \\
\hline & \multicolumn{6}{|c|}{ Aceitação de atributos ${ }^{(3)}$} \\
\hline Aparência & $7,5 \mathrm{a}$ & $3,7 d$ & $7,2 \mathrm{a}$ & $7,0 \mathrm{ab}$ & $6,2 \mathrm{bc}$ & $5,6 \mathrm{c}$ \\
\hline Aroma & $7,3 \mathrm{a}$ & $5,3 \mathrm{c}$ & $7,0 \mathrm{a}$ & $6,5 \mathrm{ab}$ & $6,5 \mathrm{ab}$ & $6,2 \mathrm{~b}$ \\
\hline Sabor & $7,9 \mathrm{a}$ & $5,3 b$ & $6,7 \mathrm{a}$ & $6,9 \mathrm{a}$ & $6,6 \mathrm{a}$ & $6,7 \mathrm{a}$ \\
\hline Textura & $7,4 a$ & $4,4 \mathrm{c}$ & $6,7 \mathrm{ab}$ & $7,2 \mathrm{a}$ & $5,9 \mathrm{~b}$ & $6,8 \mathrm{a}$ \\
\hline Global & $7,4 a$ & $4,5 \mathrm{c}$ & $6,9 \mathrm{ab}$ & $7,0 \mathrm{ab}$ & $6,4 \mathrm{~b}$ & $6,6 \mathrm{~b}$ \\
\hline
\end{tabular}

${ }^{(1)}$ Médias seguidas de letras iguais, nas linhas, não diferem pelo teste de Tukey, a $5 \%$ de probabilidade. ${ }^{(2)}$ Valores médios de três repetições e 10 julgadores treinados. Escala não estruturada de $15 \mathrm{~cm}$, intensidade crescente da esquerda para direita. ${ }^{(3)}$ Valores hedônicos médios de 54 consumidores. Escala hedônica de 9 pontos (1, desgostei muito; 9 , gostei muito).

notas elevadas em todos os atributos. A aceitação foi influenciada pelos atributos sensoriais dos grãos cozidos de cada genótipo (Taylor \& Duodu, 2009) e confirmou que os brasileiros apreciam arroz cozido com grãos soltos e pouco macios (Ferreira et al., 2005). 'Irga 417' (irrigado) e 'BRS Primavera' (terras altas) são padrões de qualidade das classes "premium" e "superior" respectivamente (Champagne et al., 2010), enquanto $A B 101002$, uma linhagem do sistema de cultivo irrigado, é promissora para o consumo por atender a expectativa do consumidor em relação às características sensoriais de seus grãos cozidos. A aceitação, por estar vinculada às características sensoriais - principalmente as propriedades de textura, associadas às características químicas intrínsecas dos grãos de cada genótipo - não diferiu quanto aos sistemas de plantio.

\section{Conclusões}

1. Os genótipos do sistema de plantio irrigado apresentam temperatura de gelatinização baixa, e os genótipos de terras altas, de intermediária a alta.
2. As características sensoriais de aparência solta e textura firme e a aceitação do arroz cozido estão mais associadas às características químicas, intrínsecas aos grãos crus, do que ao sistema de cultivo irrigado ou ao de terras altas.

\section{Agradecimentos}

À Coordenação de Aperfeiçoamento de Pessoal de Nível Superior (Capes), por concessão de bolsa.

\section{Referências}

AOAC INTERNATIONAL. Official methods of analysis of AOAC international. 18.ed. Gaithersburg: AOAC International, 2006.

BASSINELLO, P.Z.; NAVES, M.M.V. Bioquímica e saúde humana. In: SANTOS, A.B. dos; STONE, L.F.; VIEIRA, N.R. de A. A cultura do arroz no Brasil. 2.ed. Santo Antônio de Goiás: Embrapa Arroz e Feijão, 2006. p.31-51.

BETT-GARBER, K.L.; CHAMPAGNE, E.T.; THOMSON, J.L.; LEA, J. Relating raw rice colour and composition to cooked rice colour. Journal of the Science of Food Agriculture, v.92, p.283-291, 2012. DOI: 10.1002/jsfa.4573. 
BRASIL. Ministério da Agricultura, Pecuária e Abastecimento. Instrução normativa $\mathrm{n}^{\circ}$ 6, de 16 de fevereiro de 2009. Aprova o Regulamento Técnico do Arroz, definindo o seu padrão oficial de classificação, com os requisitos de identidade e qualidade, a amostragem, o modo de apresentação e a marcação ou rotulagem. Diário Oficial [da] República Federativa do Brasil, Brasília, DF, 17 fev. 2009. Seção 1, p.3.

BRASIL. Ministério da Agricultura, Pecuária e Abastecimento. Serviço Nacional de Proteção de Cultivares (SNPC). Disponível em: $\quad<$ http://extranet.agricultura.gov.br/php/snpc/cultivarweb/ cultivares_protegidas.php>. Acesso em: 15 jun. 2015.

CHAMPAGNE, E.T.; BETT-GARBER, K.L.; FITZGERALD, M.A.; GRIMM, C.C.; LEA, J.; OHTSUBO, K.; JONGDEE, S.; XIE, L.; BASSINELLO, P.Z.; RESURRECCIÓN, A.; AHMAD, R; HABIBI, F.; REINKE, R. Important sensory properties differentiating premium rice varieties. Rice, v.3, p.270-281, 2010. DOI: $10.1007 / \mathrm{s} 12284-010-9057-4$.

CUEVAS, R.P.; DAYGON, V.D.; CORPUZ, H.M.; NORA, L.; REINKE, R.F.; WATERS, D.L.E.; FITZGERALD, M.A. Melting the secrets of gelatinisation temperature in rice. Functional Plant Biology, v.37, p.439-447, 2010. DOI: 10.1071/FP09258.

FERREIRA, C.M.; PINHEIRO, B. da S.; SOUSA, I.S.F. de; MORAIS, O.P. de. Qualidade do arroz no Brasil: evolução e padronização. Santo Antônio de Goiás: Embrapa Arroz e Feijão, 2005. 61p.

FITZGERALD, M.A.; BERGMAN, C.J.; RESURRECCIÓN, A.P.; MÖLLER, J.; JIMENEZ, R.; REINKE, R.F.; MARTIN, M.; BLANCO, P.; MOLINA, F.; CHEN, M.-H.; KURI, V.; ROMERO, M.V.; HABIBI, F.; UMEMOTO, T.; JONGDEE, S.; GRATEROL, E.; REDDY, K.R.; BASSINELLO, P.Z.; SIVAKAMI, R.; RANI, N.S.; DAS, S.; WANG, Y.J.; INDRASARI, S.D.; RAMLI, A.; AHMAD, R.; DIPTI, S.S.; XIE, L.; LANG, N.T.; SINGH, P.; TORO, D.C.; TAVASOLI, F.; MESTRES, C. Addressing the dilemmas of measuring amylose in rice. Cereal Chemistry, v.86, p.492-498, 2009. DOI: 10.1094/CCHEM-86-5-0492.

FONSECA, F.A. da; SOARES JÚNIOR, M.S.; CALIARI, M.; GARCIA, D.M.; BASSINELLO, P.Z.; EIFERT, E. da C. Efeito da temperatura e do tempo de imersão da etapa de encharcamento sobre a cor dos grãos de arroz parboilizado de cultivares de terras altas. Semina: Ciências Agrárias, v.32, p.221-234, 2011. DOI: 10.5433/1679-0359.2011v32n1p221.

GARCIA, D.M.; BASSINELLO, P.Z.; ASCHERI, D.R.P.; ASCHERI, J.L.R.; TROVO, J.B.; COBUCCI, R. de M.A. Cooking quality of upland and lowland rice characterized by different methods. Ciência e Tecnologia de Alimentos, v.31, p.341-348, 2011. DOI: 10.1590/S0101-20612011000200010.

JOLLIFFE, I.T. Principal component analysis. 2.ed. New York: Springer-Verlag, 2002. 488p. (Springer series in statistics). DOI: 10.1007/b98835.

KAMINSKI, T.A.; BRACKMANN, A.; SILVA, L.P. da; BENDER, A.B.B.; SPERONI, C.S. Composição química e alterações estruturais do arroz irrigado durante o armazenamento. Semina: Ciências Agrárias, v.34, p.1167-1185, 2013. DOI: 10.5433/1679-0359.2013v34n3p1167.
KENNEDY, G.; BURLINGAME, B. Analysis of food composition data on rice from a plant genetic resources perspective. Food Chemistry, v.80, p.589-596, 2003. DOI: 10.1016/ S0308-8146(02)00507-1.

LU, S.; CIK, T.-T.; LII, C.-Y.; LAI, P.; CHEN, H.-H. Effect of amylose content on structure, texture and $\alpha$-amylase reactivity of cooked rice. Food Science and Technology, v.54, p.224-228, 2013. DOI: 10.1016/j.lwt.2013.05.028.

MARTIN, M.; FITZGERALD, M.A. Proteins in rice grains influence cooking properties! Journal of Cereal Science, v.36, p.285-294, 2002. DOI: 10.1006/jers.2001.0465.

MARTINEZ, C.; CUEVAS, F. Evaluación de la calidad culinaria y molinera del arroz. 3.ed. Cali: Centro Internacional de Agricultura Tropical, 1989. 75p. (Serie 04SR-07.01).

MESTRES, C.; RIBEYRE, F.; PONS, B.; FALlET, V.; MANTENCIO, F. Sensory texture of cooked rice is rather linked to chemical than to physical characteristics of raw grain. Journal of Cereal Science, v.53, p.81-89, 2011. DOI: 10.1016/j. jes.2010.10.001.

NAVES, M.M.V. Características químicas e nutricionais do arroz. Boletim CEPPA, v.25, p.51-60, 2007.

NELSON, N. A photometric adaptation of the Somogy method for the determination of glucose. Journal of Biological Chemistry, v.153, p.375-380, 1944.

POLESI, L.F.; LIMA, D.C.; MORAIS, P.G.; ROMO, I.C.F.; SARMENTO, S.B.S.; CANNIATTI-BRAZACA, S.G. Caracterização físico-química, funcional e nutricional de duas cultivares brasileiras de arroz. Revista Brasileira de Tecnologia Agroindustrial, v.8, p.1262-1273, 2014. DOI: 10.3895/ s1981-36862014000100011.

SINGH, N.; KAUR, L.; SODHI, N.S.; SEKHON, K.S. Physicochemical, cooking and textural properties of milled rice from different Indian rice cultivars. Food Chemistry, v.89, p.253-259, 2005. DOI: 10.1016/j.foodchem.2004.02.032.

SOARES, P.C.; SOARES, A.A.; MORAIS, O.P. de; CASTRO, E. da M.; RANGEL, P.H.N.; CORNÉLIO, V.M. de O.; SOUZA, M.A. de. Cultivares de arroz de terras altas e de várzeas recomendadas para Minas Gerais. Informe Agropecuário, v.25, p.25-34, 2004.

STONE, H.; SIDEL, J.L. Sensory evaluation practices. 3.ed. San Diego: Academic Press, 2004. 377p. (Food science and technology international series).

TAYLOR, J.R.N.; DUODU, K.G. Applications for non-wheat testing methods. In: CAUVAIN, S.P.; YOUNG, L.S. The ICC handbook of cereals, flour, dough and product testing: methods and applications. Lancaster: DEStech Publications, 2009. p.197-235.

TIAN, Y.; ZHAO, J.; XIE, Z.; WANG, J.; XU, X.; JIN, Z. Effect of different pressure-soaking treatments on color, texture, morphology and retrogradation properties of cooked rice. LWT - Food Science and Technology, v.55, p.368-373, 2014. DOI: 10.1016/j.lwt.2013.09.020.

VIEIRA, N.R. de A.; RABELO, R.R. Qualidade tecnológica. In: SANTOS, A.B. dos; STONE, L.F.; VIEIRA, N.R. de A. A cultura do arroz no Brasil. 2.ed. Santo Antônio de Goiás: Embrapa Arroz e Feijão, 2006. p.869-900.

Pesq. agropec. bras., Brasília, v.50, n.10, p.979-988, out. 2015 DOI: 10.1590/S0100-204X2015001000014 
WALTER, M.; MARCHEZAN, E.; AVILA, L.A. de. Arroz: composição e características nutricionais. Ciência Rural, v.38, p.1184-1192, 2008. DOI: 10.1590/S0103-84782008000400049.

YANG, X.-Y.; LIN, Z.-M.; LIU, Z.-H.; AJIM, M.A.; BI, J.-G.; LI, G.-H.; WANG, Q.-S.; WANG, S.-H.; DING, Y.-F. Physicochemical and sensory properties of japonica rice varied with production areas in China. Journal of Integrative Agriculture, v.12, p.1748-1756, 2013. DOI: 10.1016/S2095-3119(13)60338-X.

ZHOU, Z.; ROBARDS, K.; HELLIWELL, S.; BLANCHARD, C. Composition and functional properties of rice. International Journal of Food Science and Technology, v.37, p.849-868, 2002. DOI: $10.1046 /$ j.1365-2621.2002.00625.x.

Recebido em 6 de março de 2015 e aprovado em 20 de agosto de 2015 